\title{
HACIA UNA LÓGICA DE LO INDETERMINADO; CREACIÓN ARTÍSTICA Y SEMIOSIS
}

\section{EM DIREÇÃO A UMA LÓGICA DO INDETERMINADO; CRIAÇÃO ARTÍSTICA E SEMIOSE}

\author{
Roberto Rodolfo Fajardo*
}

\section{RESUMEN}

Este texto explora una aplicación de la teoría semiótica de Peirce al análisis de los procesos y la reflexión sobre la pintura y el arte en general. Particularmente se concentra en su teoría de la abducción como una vía que abre posibilidades de un abordaje conceptual de la creación artística capaz de revelar aspectos que tradicionalmente no son considerados.

Palabras clave: Teoría semiótica. Procesos la pintura. Abordaje conceptual. Creación artística

\section{RESUMO}

Este texto se preocupa por aplicar a teoria semiótica de Peirce em reflexões elaboradas durante analise de processos pictóricos e arte em geral, destacando a teoria da abdução como uma via a outras possibilidades de abordagem conceitual sobre criação artística, capaz de revelar aspectos que tradicionalmente não costumam ser objeto de consideração.

Palavras-chave. Teoria semiótica. Processos pictóricos. Abordagem conceitual. Criação artística

\section{Introducción}

Este estudio objetiva e explora una aplicación de la teoría semiótica de Peirce al análisis de los procesos y la reflexión sobre la pintura y el arte en general. Se concentra en su teoría de la abducción como una vía que abre posibilidades de un abordaje conceptual de la creación artística y revela aspectos que tradicionalmente no son considerados
¿Desde una perspectiva semiótica, cómo se debe abordar la creación artística? La comprensión del proceso, del hecho y la obra artística implica una disposición o tal vez una participación sobre una "vivencia" que desde la perspectiva peirceana resulta posible como proceso lógico.

Este breve texto aborda algunas de estas cuestiones y las coloca para la reflexión. De modo alguno pretendemos una exposición conclusiva,

\footnotetext{
* Graduado em Artes Visuais, com ênfase em Pintura. Mestrado em Artes Visuais, pela UFRGS (1993), outra pós-graduação em Docéncia Superior, pela Universidad de Panamá (1997) e um Doutorado em Artes Visuais pela UFRGS (2005). Atua no Curso em Bellas Artes y es vicedecano de la Facultad de Bellas Artes de la Universidad de Panamá. E-mail: <fajard_59@hotmail.com>
} 
apenas nos atrevemos a ver sobre un horizonte que nos depara nuevos desafíos.

Una aproximación racional al proceso artístico supone dos condiciones que generalmente $\mathrm{y}$ en relación a su aspecto creativo, se han considerado antagonistas, pero que sin embargo a la luz de las premisas establecidas por Peirce, se hacen complementarias y así, completamente lógicas. Se trata de la concepción del proceso artístico desde una perspectiva programática, o si se prefiere operativa y normativa, como práctica. $\mathrm{Y}$ desde una perspectiva reflexiva, en cuanto pensamiento y análisis, lo que Pareyson (1984, p. 21) ,respectivamente denominó: poética y estética.

En el caso del artista, este proceso se le presenta como premisa clara, por cuanto que para el artista existe una dimensión del hacer, que no siempre coincide con los procesos silogísticos de la dimensión del pensar. Con respecto a esto, el artista ciertamente argumentará que su proceso creativo no sigue un orden de inferencias definidas y programadas, que es tomado por una "fuerza" de la cual es medio de expresión o en lo mínimo, que aquello que hace se origina en un "insight" que le permite la creación de la obra. Y tal vez, probablemente tenga toda la razón.

\section{Obra de arte, razón e procesos creativos}

El problema no consiste en que la obra del arte sea un producto racional o no y sí en el hecho de que no percibimos que lo que está atrás de la creación artística, está también atrás de todo proceso de la razón como su fuente primordial. "La actividad creadora del ser humano no es una actividad más de entre todas las que realiza, exclusiva de la ciencia o del arte, sino una característica central de su razón", y lo que trata BARRENA, en "La Creatividad en Charles S. Peirce". Signos en Rotación, III/181.

Y exactamente de esto se trata, de la comprensión del proceso creativo como un proceso que implica siempre lo "indeterminado".

Esta cuestión de lo "indeterminado" como fuente y posibilidad de todo conocimiento, a mi parecer, refleja uno de los aportes más significativos de la teoría del signo de Peirce, esto es; la idea de que aquello que no podemos comprender como situación absolutamente lógica, sea precisamente el origen de toda posibilidad lógica.

El proceso lógico parece una búsqueda por determinar la especificidad de aquello que conocemos como separado de la multiplicidad de las posibilidades cognitivas de nuestro ser. De allí, la necesidad de los filósofos griegos de establecer las estructuras fundamentales del conocimiento conocidas como categorías. Evidentemente en la medida en que las categorías responden a una imperiosa necesidad de clasificación del caos de la percepción multisémica, es natural, que el aspecto privilegiado del nuevo constructo sea exactamente su posibilidad de terceridad. De allí que toda especificidad se fundamente sobre una convención específica, aquella que determina el contexto y los referentes del asunto en cuestión. También es natural que la condición "indeterminada" que da origen a toda posibilidad cognitiva tienda a ser exilada del nuevo constructo, pues la nueva condición debe manejarse sujetada a parámetros específicos.

La práctica de la pintura y de toda arte, supone un adiestramiento que corre por dos vías, una referente al adiestramiento en las posibilidades técnicas de la expresión y la otra referente a una capacidad de "encontrar" un signo que represente de hecho una creación estética; como descubrimiento.

Desde la perspectiva del análisis de la pintura en cuanto signo, se hace necesario establecer una estrategia de aproximación que permita verificar, en el ámbito de lo expuesto hasta ahora, una cierta especificidad.

¿Será posible hablar de una especificidad de la pintura?

¿Donde ella reside? forma?

¿En su condición de objeto, de imagen, de

La primera condición necesaria y materialmente evidente de la pintura parece ser ese su carácter bidimensional de la imagen, pues se trata siempre de una representación en dos planos. Todavía, desde la perspectiva del pintor, en un primer momento, sería posible identificar la manifestación de una "sustancia", una cierta naturalidad de la relación fenomenológica que se establece entre el signo y el objeto, que el artista parece percibir como una "analogía de las apariencias". 
Entretanto a partir del Empirismo una nueva concepción es agregada; la de una conexión constante entre determinaciones simultáneas dadas por la experiencia. Así, el concepto de sustancia implicará en una idea de necesidad y de causa en cuanto conexión constante entre las ideas de función y relación. (ABBAGNANO, 2000, p. 925-927).

Podría decirse que para el pintor toda posibilidad de expresión se le presenta como una "apariencia" como dise Ferrater Mora, "Aparecer significa dejarse ver, manifestarse" (2004, p.189).

Lo que puede considerarse en cierto grado natural, si consideramos el hecho de que su campo de expresión es la imagen visual. La apariencia manifestada como expresión artística implica una operación de identificación de formas semejantes y formas diferenciadas con respecto a lo que se puede de hecho ver, pensar o imaginar. Hay aquí un proceso particular, que no por serlo, deja de permanecer como un sustrato en la propia construcción de modos y modelos cognitivos.

La imagen expresada en una tela pictórica es tanto el pigmento como sus diluyentes que resultan en colores y formas. Es también todo posible significado que se articule en ese proceso polisémico y que se articula mediante una operación que, como ya hemos mencionado, se inicia por la identificación de oposiciones y semejanzas formales.

Se trata de una operación que, como modo transformativo, emula la propia naturaleza a través de su capacidad de representar, o si se prefiere a través de su proceso de semiosis. Se trata de una analogía que se refiere a una relación especial entre la forma creada en cuanto forma artística y su objeto. Objeto este que en su condición de signo remite a otras formas, lo podríamos referir, por ejemplo, a la construcción del imaginario del artista, y a través de él, al de la colectividad, cuyo medio de ser (en cuanto sustancia) será esa su condición de imagen.

\section{Analogía de las apariencias}

Esta "analogía de las apariencias" está íntimamente relacionada con el concepto de signo icónico en Peirce. Recordemos que el concepto de signo icónico se origina en la tricotomia "Icono, índice y símbolo" que presentan funciones diferenciadas a pesar de complementarias y que corresponden a las categorías tripartitas a las cuales los objetos semióticos están sometidos; primeridad. segundidad y terceridad.

Según Peirce, un signo es un icono de su objeto en la medida en que este presenta una propiedad irreducible, referida a su condición de "quale", o sea; de primeridad. La primera condición implícita en la identidad de tal signo es una especie de similaridad, de semejanza o analogía sobre algún aspecto de su objeto.

Un icono es un signo que se refiere a su objeto, que denota apenas en virtud de sus propios caracteres, que el igualmente posee ya sea que este objeto exista o no. Es cierto que, a menos que realmente exista un tal objeto, el icono no actúa como signo, lo que nada tiene a ver con su carácter de signo. Cualquier cosa sea una cualidad, un existente individual o una ley, es icono de cualquier cosa, en la medida que sea semejante a esa cosa e utilizado como signo. (CP 2.247).

La tela pintada, en su conjunto de elementos formales, si la consideramos en su condición de un objeto material visual, denuncia una gran variedad de signos, pero como tal, también lo es de un existente individual. La naturaleza de su imagen, aquello que es enunciado en el plano de la expresión, alude a una cualidad (quale), en este sentido tal imagen puede ser considerada un cuali-signo. Peirce para referirse a esta relación de primeridad, ya de algún modo presente en el existente individual, la designa hipoicono (CP 2.276).

La condición del hipo-icono en cualquier circunstancia, parece entonces, estar determinada por esta "semejanza" mencionada por Peirce. Y esta semejanza refiere a un "quale" que siendo un impulso primero solo puede ser actualizado como conciencia. Existe aquí una relación de primeridad que implica una operación fenomenológica, que tiene como fuente lo "indeterminado" y cuya condición de determinación primera, es la conciencia.

Peirce establece el concepto de

[...] conciencia del quale" para designar esta unidad fenomenológica básica de la percepción, y que implica una "sustancia" necesaria a cada elemento percibido "Cada quale es en sí mismo lo que es para sí mismo, sin referencia a ningún otro. (CP 6.224). 
De hecho, esta es una constatación que todo pintor puede manifestar, en la medida en que su hacer es el hacer que hace posible el hipo-icono, cuya naturaleza básica es la posibilidad de la posibilidad.

La ocurrencia de una cualidad en el tiempo y en el espacio hace de la cualidad en gran medida un sin-signo. Cualquier ejemplo de cualidad ya es un sin-signo (sin-signo icónico), entonces, el cuali-signo icónico no pasa de un posible. Es por esta razón que Peirce establece las diferencias entre sin-signo icónico (o hipo-iconos) e icono propio hasta el límite del icono puro. A pesar de que estas distinciones puedan, a primera vista, parecer bizantinas, si es la noción del icono puro una excrecencia o devaneo idealista, el examen cuidadoso de las sutiles diferencias establecidas por Peirce podrán revelarnos la importancias de las consecuencias que de ella puede ser extraídas. (SANTAELLA, 1995, p. 144).

Por esto, la naturaleza de la imagen visual, como tal, a pesar de ser viable por la especificidad de la pintura, esto es, por su cuestión bidimensional, antes de cualquier cosa revela una existencia anterior, una existencia como posibilidad, en la medida en que es precedida por su existencia en la mente de su creador. Pero una posibilidad, que en cuanto imagen resulta autónoma, en cuanto potencialmente posible.

Una imagen es, efectivamente, un objeto puramente virtual. Su importancia reside en el hecho de que no la usamos para orientarnos en dirección a algo tangible y práctico, pues la tratamos como una entidad completa con relaciones y atributos únicamente visuales. Ella no tiene otros, su carácter visual es su ser entero. (LANGER, 2003, p. 50).

En este sentido, la imagen artística es la percepción de una posibilidad, abstraída de su ocurrencia actual en el tiempo y en el espacio. Es un puente entre aquello que como posibilidad pasa a lo dimensional, aquello que determina la naturaleza de la sustancia de la pintura. "Un icono es entretanto, estrictamente una posibilidad y así, la posibilidad de ser representado como posibilidad y la posibilidad de la posibilidad en cuestión" ( $C P$ 2.311).

Así, podemos sustentar que la especificidad de la pintura no se limita, ni puede ser explicada por esta cuestión de su condición de imagen bidimensional, pues precisamente en esa condición ella denota procesos complejos que nos remiten a una situación primera.

En la pintura, la imagen como icono muestra una semejanza que se fundamenta sobre algún aspecto que denota el objeto. Aspecto, en el sentido de que se establece aquí una relación de semejanza basada en un modo de percepción sobre parte o partes del objeto, pero también como un modo de detectar un determinado modo de construcción, donde el medio de acceso fundamental es siempre la forma, es decir la imagen. Una posible analogía de esta relación implica una semejanza de naturaleza isomórfica, tanto en la configuración de sus preceptos, como en los recursos que están implicados para la percepción, la expresión y la comunicación. Esta naturaleza isomórfica parece ser una condición necesaria de toda semiosis.

En la condición de hipo-icono, toda obra artística denota una analogía con la propia construcción poética, que adviene del imaginario y de la intencionalidad del artista. En cuanto imagen, de algún modo toda pintura es análoga a esta construcción y es en este contexto donde encontrará su condición de semejanza y de analogía. Es como si sobre toda indeterminación posible esta "analogía de las apariencias", como si fuera una red lanzada al vasto mar, permitiera "pescar" elementos potencialmente significativos. Elementos que se identifican como "quales". Resulta de esto el vasto mundo de posibilidades de significación de los elementos sígnicos que conforman la obra de arte, posibilidades que están siempre en una perpetua renovación. Y cuya condición de significación potencial necesariamente prevé la indeterminación en cuanto como campo de posibilidades.

El concepto de Icono en Peirce remite invariablemente a la cuestión del quale. Como sabemos, el cuali-signo es una pura posibilidad cualitativa positiva que solo podrá materializarse a través de un existente. Por esto el carácter icónico de un signo implica una concepción amplia y comprende en su seno formas no visuales, como las formas acústicas táctiles y hasta formas conceptuales de semejanza sígnica (SANTAELLA; NOTH, 2001, p. 38). De modo que podamos considerar que la imagen visual sea una forma de icono, a pesar de que el icono no pueda ser explicado solo en términos de la imagen visual. 
La semejanza, entonces, se entiende como una construcción realizada por signos que comparten, siguiendo las ideas de Peirce, una "identidad de caracteres", en este sentido la semejanza de caracteres a partir de la determinación del artista funciona como el resultado de un proceso poético que articula esa correspondencia. De esta forma en la pintura los elementos básicos de expresión guarden una relación directa con la propia expresión, esto es, como unidades perceptivamente y culturalmente codificadas. Todavía, estos elementos guardan en sí mismo una capacidad de significación, como ya lo hemos mencionado, siempre abierta.

Cualquiera de los objetos de la naturaleza se asemejan y de hecho, entre ellos mismos, tanto cuanto cualquiera otro de los objetos. Es solo con respecto a nuestros sentidos y necesidades que una semejanza cuenta más que otra. Semejanza es una identidad de caracteres. Y esto es lo mismo que decir que la mente reúne las ideas semejantes en una sola noción. (CP 1365).

Esa condición de "quale", en cuanto especificidad, es una característica implícita en la expresión plástica una vez que es un instrumento de la expresión y la creatividad artística, evidentemente la condición de código es necesaria en la medida en que estas unidades perceptivas se refieren no solo a una semejanza construida por la visión en su proceso de identificación y si a toda sensación que pueda llevar a un acto de significación, sea a través de los sentidos o de los procesos internos de nuestra mente.

Resulta lo mismo para una análisis psicológico o epistemológico; las formas fundamentales de relación remiten a cualidades de la conciencia. Tan simple e irreducible a otras como lo son las simples cualidades sensibles; los elementos que se derivan de las sensaciones de la vista, oído o tacto. (CASSIRER, 1998. v. 1, p. 37).

La propia experiencia cotidiana se expresa en términos fenomenológicos como posibilidad en el tiempo y en el espacio, necesariamente esa experiencia en su devenir se presenta como "descubrimiento", el rompimiento de la cadena normal del comportamiento, del hábito, hace posible la condición creativa. Esta es la base del concepto de Abducción en Peirce. Por esto el mecanismo de la creación en el Arte consiste en una exploración de aquello que está "fuera del signo", en el sentido de que se refiere al rompimiento de una regla.

Así, la semiosis artística consiste en la aprehensión de un sentido cuya naturaleza de primeridad es constantemente revistada, ya sea en la realización de la obra (segundidad) o en su apreciación (terceridad). En términos cognitivos el hecho artístico solo es posible como inferencia abductiva y solo puede dirigirse para aquello que identificamos como vivencia.

Dilthey. Ges. Schriften, VII, p. 230, citado por Ferrater Mora, (2004, p. 3714) expone,

La vivencia -escribe Dilthey- es un ser cualitativo, una realidad que no puede ser definida solo por lo que es captado en nuestro interior, y que, por otra parte, también alcanza aquello que no se tiene, indiscriminadamente (...) La vivencia de algo exterior o del mundo exterior se presenta para mí de un modo análogo con aquello que no es captado y que solo puede ser inferido

Indeterminación y vivencia encuentran nexos comunes al momento de la creación artística, solo podemos crear en función de lo vivido y en aras de lo posible, posibilidad que encuentra su actualización al confrontarse con lo indeterminado.

Los caminos abiertos por las premisas que el concepto de abducción nos permite visualizar, hacen posible una aproximación a la obra del arte y al propio proceso creativo desde la perspectiva de la vivencia, pero a través ya de una operación que se reconoce en su racionalidad. Aquí resulta posible sentir y pensar al mismo tiempo. Resulta posible una experiencia racional del arte y una experiencia sensible de la razón, pero también una experiencia que puede en cualquier circunstancia conservar ese su aspecto primigenio y creativo, base de todo posible conocimiento. Resulta evidente que para Peirce el proceso analógico como un proceso básicamente sensible es fundamental para producir descubrimientos, la analogía como operación denuncia no solo un modo de comparación entre semejanzas y diferencias y sí, una estructura básica del propio proceso cognitivo, sobre la cual se ha construido todo el saber humano. Y que paradigmáticamente muestra su actualidad en la medida en que todo proceso creativo nos lleva a través de una vía de lanzamiento en el percipuum de lo indeterminado. 
Solo el acaso puede llamarlo (al percipuum como cualidad de sentimiento) pues nace de la sintonía del encuentro, conjunción de un cierto precepto con un cierto estado del espíritu, recogidos ambos en el coagulo de un instante certero. Eso tiene sabor a eternidad. De allí su desprendimiento del tiempo y el espacio. (SANTAELLA, 1995, p. 71).

\section{Referencias}

ABBAgnano, N. Dicionario de filosofía. Sao Paulo: Martins Fontes. 2000.

BARRENA, S. La Creatividad en Charles S. Peirce. Signos en rotación, Año III, n. 181, 2001.

CASSIRER, E. Filosofía de las formas simbólicas. México: Fondo de Cultura De Cultura Económica, 1998.

FERRATER M. J. Diccionario de filosofia. Barcelona: Ariel, 2004.

LANGER, S. Sentimento e forma. São Paulo: Perspectiva, 2004.

PAREYSON, L. Los problemas de la estética. Sao Paulo: Martins Fontes, 1984.

PEIRCE. C. S. Collected papers. Edited by Charles Hartshorne, Paul Weiss; Arthur Burks. Cambridge: The Belknap Press of Harvard University Press, 1931/65.

SANTAELLA, L. A teoria geral dos signos. São Paulo: Editora Atica, 1995.

SANTAELLA, L; NOTH, F. Imagem: cognição, semiótica e mídia. São Paulo: Iluminuras, 2001.

Data de submissão:15/06/2012

Data de aceite: 19/10/2012 